\title{
Significant of Mathematics Laboratory Activities for Teaching and Learning
}

\author{
Kaushik Das ${ }^{1}$ \\ ${ }^{1}$ Assistant Professor (CWTT, Govt. Aided College Approved) of B. Ed. Department, \\ Gobardanga Hindu College, City- Gobardanga, P.O.-Khantura, Dist- North 24 Parganas, \\ India
}

Email:kaushik.das53@gmail.com,drkaushikmath@gmail.com

\begin{abstract}
The present study examined the significance of the Mathematics Laboratory for Mathematics teaching in Schools, Colleges \& Teacher Training Institutes in India. Researchers present the overview of Math-Lab for effective mathematics teaching and discuss the important roles of the mathematics laboratory for mathematics learning. The mathematics laboratory classroom solves this problem by combining these environments. Laptop computers address the needs of software and networking but there are fewer pro levels that help maintain a more balanced classroom environment. In the teaching and learning of mathematics, the mathematics laboratory, with the support and companionship of both the student-teachers, can play a significant role and can have a significant impact on the progress of the students in mathematics. The main objective of the present study is to find out the major factors of Mathematics Laboratory in Mathematics-Education. This study discusses the concepts of mathematics in the classroom, the mathematics laboratory and its importance, and how to use the mathematics laboratory for trained teachers, from beginning to elementary level mathematics education. The methodology of the study is a mixed type involving an interpretative approach where qualitative data were collected and study secondary sources, like books, articles, journals, thesis, university news, expert opinion, and websites, etc. Finally, meaningful suggestions are offered.
\end{abstract}

Keywords: Learning Environment, Mathematics Education, Mathematics Laboratory, Materials of Mathematics Laboratory, Needs of Math-Lab, Teaching and Learning.

\section{INTRODUCTION}

In India, education is considered as a tool of socio-economic and political development, and it is given due attention. Teaching is a complex mix of systems that influence what happens in the classroom through interactions between teachers, students, curriculum, schools, colleges, universities, local settings, and others. Agbaga observes that the problem of ineffective learning can be solved through the mathematical laboratory planning and intelligent application (Agbaga, 1997). Mathematics Education helps to form a logical thinking and critical framework, making it an effective and necessary tool for cultural and human growth to any nation. Interpretation, comparison, exploration, reasoning process of solution strategies, which encourages the development of rational, adaptive reasoning for laboratory methods and specific tasks (Kilpatrick, 2001). Through the Mathematics Laboratory, it is possible to create activities that encourage the transformation of intuitive concepts and early elementary operation levels into more advanced thinking. Starting in elementary school, they should strive to build knowledge about subjects, classes and their tasks through the analysis of mathematical practice, critical review and formative analysis. Historical events in mathematics are consistently related to the results of the study with cognitive, religious, and cognitive aspects related to laboratory activities. (Bartolini \& Mariotti, 2008; Martignone \& Antonini, 2009), Mathematics is not fixed beyond the reality of time. But like other sciences, it has a history. Especially in middle school girl students, the most poorly educated in mathematics, widely hated, and abnormally low-key subjects, run away from it. (Ukeje, 1986). This 
changes regularly, so it is important to evaluate students' experiences and knowledge, discoveries, collaborative learning. These teachings must also be practiced, discussed, explored, developed through thought and the way knowledge is formed. The mathematics laboratory is usually an incentive to focus on the specific needs and needs of the mathematics teacher, depending on the different classes. The Mathematics Laboratory is a place where students can learn and explore different mathematical concepts and validate different mathematical data and theories using different activities and elements (Igbokwe, 2000). For teaching and learning mathematics, computers can offer something qualitatively different, that is, the experience of a 'mathematics laboratory' in which mathematical statements are used as active objects to produce results (Kent et al., 1994). The study of effective mathematics in the classroom is one in which students and teachers interact in ways that give students the greatest opportunity to maximize how much they can learn. Mathematics carries with it the values we are constantly associated with (Burton, 1994). These are the ways students and teachers interact in a learning environment. Some conversations result in classroom discussions of student learning, teachers and students begin questions. Mathematical nature requires basic skills to properly understand and adequately utilize the growing amount of scientific and technical knowledge in everyday life. Adequacy of laboratory facilities and academic performance in basic-science (Okeke, 1995). A math lab is a place where students can explore and validate mathematical data and theorems through a variety of activities using various materials such as mathematics, shapes, formulas, datasets, and symbols.

\section{OBJECTIVES OF THE STUDY}

$>$ Examine the overview of the Mathematics Laboratory.

$>$ To find out the connection of Mathematics \& Mathematics Laboratory.

$>$ Find out the relationship of Mathematics Laboratory with mathematics lessons in the classroom.

$>$ Examine the need for the Math Laboratory.

\section{STATEMENT OF THE PROBLEM}

This study was aimed at examining the significance of Mathematics Laboratory for teaching and learning mathematics. This is an area that has been researched however there are certain as facts that research has not attended yet. Overview of many aspects of attitudes towards mathematics including a review of instructional is still unclear how the Mathematics Laboratory affects the development of studies' attitudes towards mathematics. As a result, the researcher believes that it is important to investigate and identify factors influencing students' attitudes towards mathematics subjects. Therefore, the present study was motivated to access whether the perceptions of Mathematics students toward mathematics played any role in their attitudes towards mathematics. The present study was structured to investigate from each student the most important school \& College-related determinants of likely and disliking mathematics. The particular value of the present study is that it should identify and categories different perceptions and outcomes of different students.

\section{PURPOSE OF THE STUDY}

The importance of this study is that it will help to identify the availability of laboratory facilities in schools, Colleges \& Teacher Training Institutes as well as the impact these facilities have on the effective teaching and learning of Mathematics, Integrated Science and Computer. It will also analyze critically some factors that affect the individual performance of students in the selected schools. Finally, the researcher proffers a solution for those that will read and implement the work.

\section{SIGNIFICANCE OF THE STUDY}

The importance of this study is that it will help to identify the availability of laboratory facilities for effective teaching and learning of Mathematics, Integrated Science and Computer Science in India Government of West Bengal. This study would also help to provide some information for curriculum designers and classroom teachers in order to utilize facilities provided for them and other relevant 
approaches to enhance meaningful learning of Mathematics, Integrated Science and Computer Science by students. Thus, the knowledge of students' cognitive style and attitude would be very useful in both academic and career enhancement.

\section{METHODOLOGY OF THE STUDY}

This study employs an interpretative approach where qualitative data were collected and analyzed by the document study of the research papers from journals, reports, books, edited books, and online documents. The methodology of the proposed study is based on the document-based analysis.

\section{METHODOLOGY EMPLOYED}

- It is based on qualitative research.

- It has the chief characteristics of recent document-based analytical research.

\section{RESEARCH MATERIALS}

- Government documents,

- Peer reviewed Journals

- Books,

- Magazines,

- On-line documents from some relevant and reliable internet sources.

\section{DATA COLLECTION PROCESS}

Multiple procedures have been employed including studying international and national journals, library consultation, online journals, periodical, newspapers and documents.

\section{DATA ANALYSIS}

Historical and sociological approaches have also been adopted for analyzing the collected data. No statistical analysis has been furnished.

\section{RESULTS}

\section{Mathematics:}

The quantities, structures, places and changes are studied according to the nature of mathematics. It was developed to establish morphological ideas through the use of abstraction and logical reasoning from the calculation, calculation, measurement and study of the size and motion of physical objects. The element of the effective pronunciation of abstract elements of science that drives the development of a nation's technology is based on mathematics. The inevitability of mathematics cannot be overemphasized in the daily activities of people; thus, all scientific and technological advancements and advances are considered as the basis for all human development activities.

\section{Some definitions:}

The study of the measurement, properties, and relationships of quantities and sets, using numbers and symbols. (American Heritage Dictionary: 2000).

Mathematics is the science of structure, order, and relation that has evolved from elemental practices of counting, measuring, and describing the shapes of objects. (Encyclopaedia Britannica: 2010).

According to Oyekan (2000), "instructional materials are those things that can facilitate effective teaching and pleasant learning that is teaching aids through which learning process may be encouraged and motivated under the classroom situation". These enhance the teaching-learning process when adequately and appropriately used.

Mathematics Laboratory:

The Math Laboratory is a unique concept in mathematics education. The Mathematics Laboratory was launched on the 5th. It has come a long way in enriching mathematics at the primary, secondary and senior secondary levels. The mathematics laboratory has a considerable influence on the intellectual knowledge of mathematics, and it is noticed in the teacher-learning institute as well (Das, 2019). In 
developed countries, math labs are an integral part of the regular curriculum. The Mathematics Laboratory is a place where students can learn and explore mathematical concepts. Here students can validate mathematical data and theorems through various activities using different materials. Through these activities, the teacher can explore his students, learn, foster interest and develop a favorable attitude towards mathematics. A math lab is a place where we find a collection of games, puzzles, teaching aids and other materials for managing activities. Both of these are meant to be used by the student himself and his teacher to discover the world of mathematics, to learn and to develop an interest in mathematics. Mathematics Laboratory is more effective than the lecture method in teaching and learning mathematics concerning students' achievement. Mathematics Laboratory is further seen to enhance students' ability to carry out their projects and other activities that provide active sensory mathematical experiences at any stage. The teaching and learning of mathematics concepts should be by practical, exploration and experiment, using a mathematics laboratory. This will construct the students organize their true potentials, cultural habits, talents, cultivate habits of hard work, high moral, ethical standards to learning mathematics and description of its value system to real-life situations and national economic growth.

Need and Importance of Mathematics Laboratory:

A math lab is a place where mathematical activities are practically conducted, and is similar to any other science laboratory. Some of the ways in which a mathematics laboratory can contribute to the learning of the subject are.

- It helps the students to build interest and confidence in learning the Mathematics subject.

- It gives an opportunity students participation in the process of learning and becoming autonomous learners.

- Mathematics Laboratory provides opportunity to exhibit the relatedness of mathematical concepts with every-day life.

- It provides an opportunity to understand and internalize the basic mathematical concepts through concrete objects and situations.

- It enables the students to verify or discover several geometrical properties.

- It helps the students to using models or by paper cutting and folding technique.

- It offers greater involvement of both the mind and the hand, which facilitates perception.

- Mathematics Laboratory encourages students to think, discuss, and interact with each other.

- It gives more integrate ideas in a more effective way.

\section{Mathematics Laboratory can contribute to the learning of the subject are:}

$\checkmark$ Teachers need to pay attention to both the testing technique and the evaluation technique.

$\checkmark$ Importantly, it allows variety in school mathematics learning.

$\checkmark \quad$ Students have the opportunity to learn the rules and constraints of different puzzles and games and apply them. In this process, they became aware of the role of rules and constraints in mathematical problems.

$\checkmark \quad$ It enables the teacher to display, interpret and reinforce abstract mathematical concepts from abstract concepts of mathematics, using concrete objects, models, charts, graphs, pictures, posters, etc.

$\checkmark \quad$ It enables students to model different geometric properties and information using models or to verify or discover paper cutting and folding techniques.

$\checkmark \quad$ Establishing a Mathematics-Lab does not involve high cost. Improvised aids using inexpensive material can be made. Try to make Low-Cost Model, Chart etc.

$\checkmark$ It builds up opportunity, interest and confidence in the students in learning and doing mathematics.

$\checkmark \quad$ It helps the students to develop Meta cognitive abilities.

\section{Functions of mathematics laboratory:}

The functions of a mathematics laboratory are to

- Concretize the abstract mathematical concepts.

- Provide activities that arouse student curiosity.

- Maintains students' interest in mathematics education.

- Provide efficiency to develop proper skills in handling equipment. 
- Create interest for mathematics teaching and learning and purposeful for students.

Table-1: Methods and Materials used in the Mathematics laboratory and Mathematics Activities.

\begin{tabular}{|l|l|}
\hline \multicolumn{1}{|c|}{$\begin{array}{c}\text { Methods and Materials used in the } \\
\text { Mathematics laboratory. }\end{array}$} & \multicolumn{1}{c|}{ Activities. } \\
\hline $\begin{array}{l}\text { Paper folding. } \\
\text { Collage (Paper cutting \& pasting). }\end{array}$ & The midpoint of a line segment. \\
\hline Graph paper. & Obtain a square on a given line segment. \\
\hline Broom sticks. & The perpendicular bisector of a line segment. \\
\hline Geo-board, rubber band. & Creative expressions in designing puzzles. \\
\hline Unit Cubes (wooden or any material). & Find median of a triangle. \\
\hline Pins \& threads. & To find out the area of a rhombus \\
\hline Transparency sheets, cello tape. & $\begin{array}{l}\text { To verify the identity } a^{3}+b^{3}=(a+b)\left(a^{2}-a b+b^{2}\right), \text { for simple } \\
\text { cases using a set of unit cubes. }\end{array}$ \\
\hline Chart papers, glazed papers, sketch pens. & $\begin{array}{l}\text { Comparison of the performance of two teams in a one-day } \\
\text { international Cricket match. }\end{array}$ \\
\hline Drawing instruments. & $\begin{array}{l}\text { To verify the midpoint theorem for a triangle, using paper } \\
\text { cutting and pasting. }\end{array}$ \\
\hline Surveying instruments. & The perpendicular to a line from a point given outside it. \\
\hline
\end{tabular}

\section{Teacher Education to Classroom Implementation:}

In all teaching examinations, teachers design and conduct laboratory activities to encourage students to monitor their progress and criticism. In higher grades, laboratory activities are similar to teacher education workshops. There is a need to connect the growth of information and communication technology with mathematics learning (Das, 2019). Focusing on the content of mathematics and the cultural aspects involved, the development of adaptive reasoning in the construction of rulers and compasses, the verbalization of the inquiry and reasoning process, and the encouragement of constructive dialogue between peers and experts. The goal was to improve teachers' knowledge of the process of learning and doing mathematics.

\section{Discussions:}

The classroom tasks aimed at fostering the development of exploration and argumentation processes. In this case, students will be prepared for future or near-future challenges in the face of problems or real problems in their learning environment and will have the necessary skills to find the right solution to this problem. Each society expects its education system to enable individuals to be effective problem solvers in their real-life (Walker \& Lofton, 2003; Chin \& Chia, 2004). Thus, instructors should analyze and evaluate trends to determine a suitable curriculum. There should be a clear method of instruction in this regard which will prepare the students for real-life situation. Working in mathematics labs with their students helps teachers explain the condition in detail in the math laboratory experience outside the classroom.

\section{Recommendations and Educational Implications:}

$>$ Mathematics Teaching could be carried out in a Mathematics Laboratory by integrating mathematics laboratory into regular curriculum from elementary level to teacher training institutions.

$>$ Mathematics student \& teachers should be trained on the variety use of mathematics laboratory in the mathematics methodology class.

$>$ Teacher built a scientific environment with the help of mathematics equipment.

$>$ Specific marks should be include for regular syllabi.

$>$ In every school Mathematics Laboratory shall be established and teaching of mathematics shall be carried out through mathematics laboratory.

$>$ Every institute should be built mathematics laboratory, its mandatory.

$>$ Specific curriculum include in Teacher-Training syllabi. 


\section{CONCLUSIONS}

This study influences the initiation of using mathematics laboratory in teaching-learning and connect with the theoretical parts. The mathematics laboratory uses a method other than the dialectic method as a platform and to have a significant impact on the technique or knowledge creation. Math lab makes teaching and learning activity-based and experimentation oriented from the elementary school stage to higher studies. Math teachers should use math lab for teaching purposes. It exhibits relatedness of mathematics concepts with everyday life in real situations. Math teachers should be trained for the use of a math lab in the class according to syllabi.

\section{REFERENCES}

1. Bartolini Bussi, M. G. \& Mariotti, M. A. (2008). Semiotic mediation in the mathematics classroom: Artifacts and signs after a Vygotskian perspective. In L. English \& al. (Eds.), Handbook of Int'l Research in Math. Educ., second edition (pp. 746-783). Routledge.

2. Martignone, F., Antonini, S. (2009). Exploring the mathematical machines for geometrical transformations: a cognitive analysis. In Tzekaki, M., Kaldrimidou, M., \& Sakonidis, H. (Eds.), Proceedings 33th Conf. of the Int. Group for the Psychology of Mathematics Education. (Vol. 4, pp. 105-112). Thessaloniki, Greece: PME.

3. Kilpatrick, J. (2001). Understanding mathematical literacy: the contribution of research. Educational Studies in Mathematics, 47, 101-116.

4. KENT, P., RAMSDEN, P. and WOOD, J. (1994) Times Higher Educational Supplement (London), 13 May 1994, supplement on 'Multimedia for teaching and learning', pp. x-xi.

5. Okeke, R.J. (1995). Principles of development selection, utilization, evaluation storage and retrieval of instructional materials. In: Okwo, F.A., \& Ike, G.A., (Eds.), Educational Technology: Basic Concepts of Issues. Nsukka: University Trust Publishers. pp. 45-76.

6. Ukeje BO (1986) Education for Social Reconstruction London, Macmillan.

7. Agwagah UNV (1997): Laboratory Approach to Mathematics I Inst- ruction: A Situation Report on Nigerian Secondary schools in The 1990s. J. Liberal Studies 5(2):116-124.

8. Igbokwe DI (2000): Dominant factors and Error Types inhibiting the understanding of Mathematics. 41st Annual Conference Proceedings of STAN, 242-249.

9. Das, K. (2019).Lack of mathematical knowledge in two-year B.Ed. programme: Indian Context. Research Journal of Educational Sciences. Vol. 7(3), 1-6, September (2019). ISSN 2321-0508.

10. Burton, L. (1994). Whose culture includes mathematics? In S. Lerman (Ed.), Cultural perspectives on the mathematics classroom (pp. 69-83). London, United Kingdom: Kluwer.

11. Das, K. PEDAGOGICAL APPROACHES IN MATHEMATICS: INDIAN PERSPECTIVES AND PRACTICES. International Journal of All Research Writings. Vol. 1 Issue. 3. September 2019. ISSN (O) - 2582-1008.

12. Das, K. et al. "Applications of Mathematical Knowledge in History, Geography, Fine-Arts \& Physical Education Subjects in Two-Year B.Ed. Program: Indian Context." Journal of Emerging Technology and Innovative Research, vol. 6, no. 6, 2019, pp. 8-15.

13. Walker, J. T. \& Lofton S. P. (2003). Effect of Problem Based Learning Curriculum on Students' Perceptions of Self directed Learning. Issues in Educational Research, 13, University of Mississipi Medical Centre.

14. Das, K. "Role of ICT for Better Mathematics Teaching." Shanlax International Journal of Education, vol. 7, no. 4, 2019, pp. 19-28. DOI: https://doi.org/10.34293/education.v7i4.641

15. Chin, C. \& Chia, L. G. (2004). Problem Based Learning using Students' Questions to drive Knowledge Construction, Science Education, 88(5), 707-727.

16. Das, K and Chowdhury. R. "Analytical Study on Practice Teaching of B.Ed. Students in B.Ed. Department, Gobardanga Hindu College, under WBSU in India." International Journal of Scientific Research and Reviews, vol. 8, no. 2, 2019, pp 3882-3898. 


\section{BIOGRAPHY}

Kaushik Das is currently working as an Assistant Professor (CWTT, Govt. Aided College Approved) of B. Ed. Department, Gobardanga Hindu College, West Bengal-743273, India. He is a commendable writer and scholar in the field of Mathematics \& Education. He has obtained B.Sc. in Mathematics from Kalyani University and M.Sc. in Mathematics from West Bengal State University, West Bengal. Also, he obtained B.Ed. \& M.Ed. He interested in Pure Mathematics, Applied Mathematics, Mathematics-Education, Teacher-Education, Science Education, Philosophy of Science and ICT. He was the center Assistant Coordinator at NIOS-DElEd study center under North 24 parganas district. He has given special lectures on various topics in more than 20 colleges. He has published more than 25 Research Articles in different National \& International Journals. He has presented more than 10 papers in several National/International Conferences/Seminars. He is a reviewer of some international journals. He is actively associated with several teaching-learning and research-oriented works in higher education. 